\title{
Influence of Two Varieties of Broad Bean and Beauveria bassiana (Blas) on Aphis fabae scop. Under Field Conditions
}

\author{
Zayoor Z. Omar', Tavga S. Rashid², Hayman Kakakhan Awla ${ }^{1 *}$ \\ ${ }^{1}$ Department of Plant Protection, Khabat Institute, Erbil Polytechnic University, Erbil, Iraq, ${ }^{2}$ Department of Plant Protection, Faculty of \\ Agriculture, Salahaddin University-Erbil, Erbil, Iraq
}

\author{
*Corresponding author: \\ Hayman Kakakhan Awla, \\ Department of Plant Protection, \\ Khabat Institute, Erbil \\ Polytechnic University, Erbil, \\ Iraq. \\ E-mail: \\ hayman.awla@epu.edu.iq
}

Received: 10 January 2019

Accepted: 21 May 2019

Published: 30 October 2019

\section{DOI}

10.25156/ptj.v9n2y2019.pp16-19

\section{A B S TRACT}

Black bean aphid (Aphis fabae scop.), belongs to order Hemiptera and family Aphididae, is one of the important pests of the Fabaceae family. Beauveria bassiana is an important biocontrol agent to replace chemical insecticides. Therefore, in this research, two different varieties of broad bean with three different concentrations of $B$. bassiana were investigated on adults of fabae aphids under field conditions. After $3,5,7$, and 14 days, the effect of the $B$. bassiana on the population of aphids was measured. The local variety was found to be more sensitive to the aphids compare with the Spain variety. In the high concentration $\left(10^{8}\right.$ spores $\left./ \mathrm{ml}\right), 80 \%$ mortality was obtained with $B$. bassiana in day 3 with local variety; then mortality increased after 5,7 , and 14 days of measuring the population of the adults. Mortality declined with the decrease in concentrations. The Spain variety was found to be resistance because fewer aphids were recorded compared to the local variety. In the highest concentration and day 14 , mortality was $100 \%$. The achieved results showed that $B$. bassiana can be used as a potential biocontrol agent for the management of black bean aphid in the fields.

Keywords: Biocontrol; Entomopathogenic fungi; Mortality; Variety; Vicia faba

\section{INTRODUCTION}

Black bean aphids are the most damaging pests of Viciafaba, in many countries. Because severe harm to Fabaceae plants, when an infestation of the crop occurs before flowering, some plants can be killed by direct feeding (Shannag, 2007).

Environmental and health problems have arisen due to using chemical pesticides throughout the world. Entomopathogenic fungi are an environmentally friendly and more approachable alternative to chemical pesticides. They are natural, less toxic with no residual activity, easy to formulate (Korunić, 2013), and less chance to develop resistance (Gould et al., 1991). Beauveria bassiana has a wide host range (Maurer et al., 1997), parasitizing insects and killing or disabling them (Butt et al., 2001; Grund and Hirsch, 2011). B. bassiana is widely distributed in all regions of the world and can be easily isolated (Akmal et al., 2013). It is also cheap to produce in large quantities and easy to store (Mascarin and Jaronski 2016).

B. bassiana has proved effective in controlling aphids, even chemical pesticide-resistant strains (Maina et al., 2018), and some strains are already available commercially for the control of various species of insects (Samish et al., 2004).
Previous studies regarding the efficacy of diverse fungal isolates for the management of aphids have shown greater success (Knudsen et al., 1990; Wang and Knudsen, 1993; James et al., 1995; Thungrabeab, 2007; Sayed et al., 2018).

Resistant faba bean cultivars against aphids have been developed, such as $V$. faba Minor, which are tolerant and resistant to Aphis fabae (Fouad and Malik 2016). However, aphids can be infested most develop cultivars; therefore, the studies of resistant mechanisms of other faba bean cultivars are directly needed. In the Kurdistan Region, very little is known on relationship between the broad bean cultivars and the $A$. fabae scop. performance. Due to the increasing threats of aphids and indirect damage by the pesticides, a study was planned to check the possible resistance traits in two selected broad bean cultivars against A. fabae scop in combination with different concentrations of B. bassiana.

\section{MATERIALS AND METHODS}

The study was carried out in 2016-2017 in Khabat Technical Institute fields. Two cultivars of broad (local and Spain) varieties were selected. The experiment was 
arranged in a randomized complete block design (RCBD) with three blocks; each block contains eight treatments (two cultivars with three concentrations of B. bassiana and one control). Plots were rectangular $\left(1 \times 1.5 \mathrm{~m}^{2}\right)$, contains four lines, each line with ten plants, the distance between blocks was $1 \mathrm{~m}$. The planting was started in November, and the treatments were applied on the March 1 and repeated once again on the March 15.

A fungal culture of $B$. bassiana was obtained from the College of Agriculture at Baghdad University. It was maintained by transferring once every 2 weeks on Sabouraud Dextrose Agar supplemented with 2\% yeast extract at $25^{\circ} \mathrm{C}$. For field tests, conidia were harvested by scraping from culture surfaces in Petri dishes. For suspension treatments, spores were suspended and mixed with $0.1 \%$ Tween 80 and vortexed for $2 \mathrm{~min}$.

Suspension at the concentrations zero (only distilled water with $0.1 \%$ Tween 80 ) as control; $1 \times 10^{2} ; 1 \times 10^{4}$; and $1 \times 10^{8}$ were prepared and applied by spray method on plants until the plants got wet using pump pressure water sprayers $-2 \mathrm{~L}$. The data were collected by taking leaves after 3, 5, 7, and 14 days of spraying the fungal suspension as noted above.

From each treatment, five plants were randomly selected and labeled for recording the aphid observations. The black aphid identified by Dr. Hisamadin Abdulla Mohamed form College of Agriculture, Baghdad University, the population was recorded on each selected plant, and mean number of aphids per plant was worked out. The aphid population was transferred to the mortality using Abbott's formula (Abbott, 1925):

$$
\text { Mortality } \%=\frac{X-Y}{100-Y} \times 100
$$

Where $\mathrm{X}=$ Percentage mortality in the treated sample and $\mathrm{Y}=$ Percentage mortality in the control.

\section{Data Analysis}

The relationship between concentrations and mortality is analyzed using ANOVA and the RCBD. Thus, it means that it was compared using Duncan's multiple range test and significant differences at 5\% probability (Ferreira, 2011).

\section{RESULTS AND DISCUSSION}

Fungal treatment showed significant mortality of $A$. fabae at $3,5,7$, and 14 days post-inoculation with $1 \times 10^{2}, 1 \times 10^{4}$, and $1 \times 10^{8}$ conidia/ml suspension of $B$. bassiana recorded [Table 1 and Figure 1]. In local variety, the minimum mortality of the aphides $(41.94 \%)$ was obtained at $3^{\text {rd }}$ day after treatment in concentration $1 \times 10^{2}$. Then, the mortality was increased at 5, 7, and 14 days $(60.14,85.97$, and $92.91 \%$ ), respectively, with the same concentration, while maximum mortality of $100 \%$ was obtained with concentration $1 \times 10^{8}$ at 14 days post-inoculation.

The Spain variety was more resistance to the aphids compare with the local variety because the lowest population of aphids was recorded. The fungal application showed effectiveness after 3 days in concentration $\left(1 \times 10^{2}\right.$ conidia/ml), which gave $10.66 \%$ mortality, while maximum mortality of $100 \%$ was recorded days post-inoculation at concentration $\left(1 \times 10^{8}\right)$ conidia/ml. No mortality was recorded after 3 and 5 days inoculation, while in contrast to this, mortality was recorded after 7 and 14 days reached $14.30 \%$ and $27.36 \%$, respectively. The cumulative corrected mortality 100\% at highest concentration $\left(1 \times 10^{8}\right.$ conidia/ml $)$ on day 14 after treatment $(100 \%)$ whereas at lowest concentration $\left(1 \times 10^{2}\right.$ conidia $\left./ \mathrm{ml}\right)$, it was $92 \%$. It is evident from the data; mortality decreased with reduced conidial concentration. As the concentration of conidia of B. bassiana increased from $1 \times 10^{2}$ to $1 \times 10^{8}$, the mortality also improved from $0.0 \%$ to $79.3 \%$ at day 3 . Furthermore, the mortality increased from $60.14 \%$ to $87.36 \%$ at day 5 , from $85.97 \%$ to $97.22 \%$ at day 7 , and from $92.91 \%$ to $100 \%$ at day 14 in the local variety. For the Spain variety, similarly when the concentration of conidia of B. bassiana increased from $1 \times 10^{2}$ to $1 \times 10^{8}$, the mortality also increased from $10.66 \%$ to $51.86 \%$ at day 3 . Moreover, the mortality increased from $63.20 \%$ to $80.8 \%$ at day 5 , from $90.40 \%$ to $97.33 \%$ at day 7 , and from $92 \%$ to $100 \%$ at day 14 .

Table 1: Effects of Beauveria bassiana on two different varieties of broad bean aphid mortality

\begin{tabular}{|c|c|c|c|c|c|}
\hline Variety & Concentration & Day 3 & Day 5 & Day 7 & Day 14 \\
\hline \multirow{4}{*}{ Local } & $\mathrm{B} 1$ & $0.0^{\prime}$ & $0.0^{\prime}$ & $14.30 \pm 4.9^{j-1}$ & $27.36 \pm 0.2 .07^{i-k}$ \\
\hline & B2 & $41.94 \pm 10.96^{\mathrm{h}, \mathrm{i}}$ & $60.14 \pm 4.75^{\mathrm{f}, \mathrm{g}}$ & $85.97 \pm 3.88^{\mathrm{a}-\mathrm{c}}$ & $92.91 \pm 5.14^{a-c}$ \\
\hline & B3 & $62.64 \pm 5.71^{\mathrm{e}-\mathrm{g}}$ & $75.00 \pm 6.41^{\mathrm{c}-\mathrm{f}}$ & $89.16 \pm 3.44^{a-c}$ & $97.22 \pm 1.83^{\mathrm{ab}}$ \\
\hline & B4 & $79.30 \pm 4.7^{\mathrm{b}-\mathrm{f}}$ & $87.36 \pm 3.04^{a-c}$ & $97.22 \pm 1.2^{\mathrm{ab}}$ & $100^{a}$ \\
\hline \multirow[t]{4}{*}{ Spain } & B1 & $0.0^{\prime}$ & $0.0^{\prime}$ & $9.33 \pm 9.31^{\mathrm{kl}}$ & $22.13 \pm 7.21^{\mathrm{jk}}$ \\
\hline & B2 & $10.66 \pm 9.49^{k, l}$ & $63.20 \pm 8.8^{8-g}$ & $90.40 \pm 4.99^{a-c}$ & $92 \pm 4.61^{a-c}$ \\
\hline & B3 & $29.87 \pm 12.81^{i, j}$ & $67.73 \pm 13.35^{d-g}$ & $92 \pm 4^{\mathrm{a}-\mathrm{c}}$ & $93.07 \pm 3.58^{a-c}$ \\
\hline & B4 & $51.86 \pm 7.7^{g, h}$ & $80.8 \pm 5.2^{\mathrm{a}-\mathrm{e}}$ & $97.33 \pm 2.66^{\mathrm{ab}}$ & $100^{\mathrm{a}}$ \\
\hline
\end{tabular}

Means in the table followed by different letters are significantly difference. B1=Control; B2=1 $\times 10^{2} ; \mathrm{B} 3=1 \times 10^{4} ; \mathrm{B} 4=1 \times 10^{8}$ 


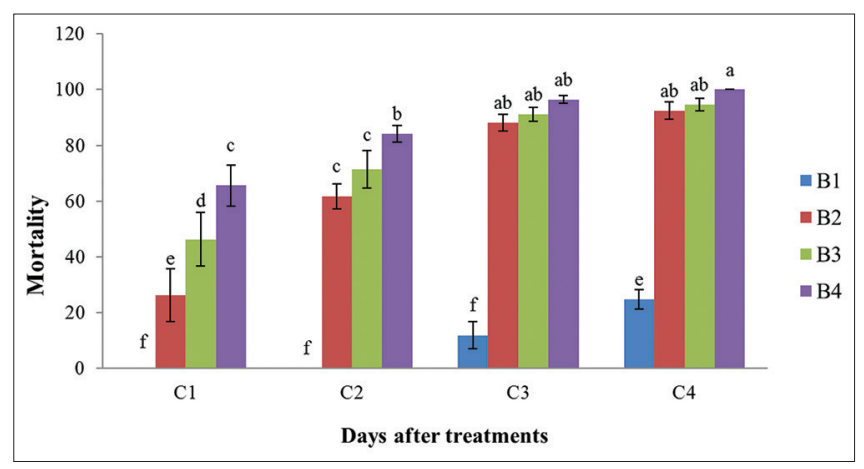

Figure 1: Aphids mortality on the broad bean leaves treated with different concentrations of Beauveria bassiana after 3, 5, 7, and 14 days of treatment

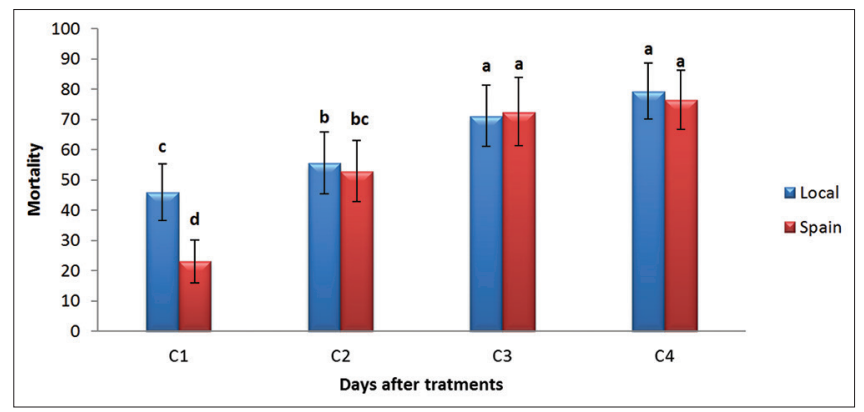

Figure 2: Number of aphids mortality on the two varieties of broad bean leaves treated with different concentrations of $B$. bassiana

The obtained results show that the fungus induced high mortality against black bean aphids. These results agree with Feng et al. (1994) who reported that B. bassiana has been widely used as antagonistic fungal agents against aphids. Furthermore, Vega (2018) studied the effects of the entomopathogenic fungus, B. bassiana, on the adult broad bean aphid declared that the $\mathrm{LC}_{50}$ and $\mathrm{LC}_{90}$ were 35.778 and 361.799 spores $/ \mathrm{ml}$, respectively, against the adult aphid. All fungal concentrations $\left(1 \times 10^{2}, 1 \times 10^{4}\right.$, and $\left.1 \times 10^{8}\right)$ after 4 days of direct treatments, caused significant mortality ranged between $26.67 \%$ and $80 \%$ (Wafaa et al., 2017).

The field trial results of this study, using B. bassiana, are similar to those of McKinnon et al. (2017) in which whole broad bean plants were inoculated with B. bassiana as an endophyte through spraying, resulting in negative effects on aphid choice and performance. Pathogenicity of B. bassiana strain used against cotton aphids in a survival experiment where $60 \%$ and $57 \%$ of treated aphids, respectively, died from infection over 7 days versus 10\% mortality among control insects (Lopez et al., 2015).

Similarly, Lopez (2015) showed that A. fabae feeding on bean plants colonized independently by strains of either B. bassiana, Trichoderma asperellum or Gibberella moniliformis reproduced poorly compared to those on control plants. Aphid's feeding on cotton leaves colonized by B. bassiana slowed aphid reproduction (Gurulingappa et al., 2010).

The $1^{\text {st }}$ day of taking data (day 3 ), the mortality was less compared to days 5, 7, and 14 which increased, respectively. The overall mortality rate was between $20 \%$ and $100 \%$. There was statistically significant association of days 3 and 14 with mortality [Figure 1]. The results of this study are similar to Saranya (2009) who studied the biocontrol of cowpea aphid Aphis craccivora (koch) using entomopathogenic fungi.

There was strong link between concentrations of B. bassiana and aphids mortality [Figure 2]. The lowest concentration $\left(1 \times 10^{2}\right)$ showed the lowest mortality and the highest concentration $\left(1 \times 10^{8}\right)$ showed the highest mortality, and there was a significant difference between them.

The results were similar to Selvaraj et al. (2012); they reported that when the conidial spore concentration increased, the mortality of aphids also increased. The highest concentration caused maximum cumulative after treatment compared to the lowest concentration.

\section{CONCLUSION}

The results have been obtained with the use of B. bassiana for control of broad bean aphid show a promising level of activity. The Spain variety is more resistance compare with the local variety. Mortality of $A$. fabae at day 14 postinoculation with $1 \times 10^{8}$ conidia/ $\mathrm{ml}$ suspension is the best time and concentration to control aphids. The findings of this study suggest that $B$. bassiana has virulent and highly potential for biological control on $A$. fabae.

\section{REFERENCES}

Abbott, W. S. 1925. A method of computing the effectiveness of an insecticide. J. Econ. Entomol. 18(2): 265-267.

Akmal, M., S. Freed, M. N. Malik and H. T. Gul. 2013. Efficacy of Beauveria bassiana (Deuteromycotina: Hypomycetes) against different aphid species under laboratory conditions. Pak. J. Zool. 45(1): 71-78.

Butt, T. M., C. Jackson and Magan, N., editors. 2001. Fungi as Biocontrol Agents: Progress Problems and Potential. Centre for Agriculture and Bioscience International, Wallingford.

Feng, M. G., T. J. Poprawski and G. G. Khachatourians. 1994. Production, formulation and application of the entomopathogenic fungus Beauveria bassiana for insect control: Current status. Biocontrol Sci. Technol. 4(1): 3-34.

Ferreira, D. F. 2011. Sisvar: A computer statistical analysis system. Ciência Agrotecnol. 35(6): 1039-1042.

Fouad, M. and Malik, L. 2016. Genetic resource of the resistance of Vicia faba L. against the black bean aphid, Aphis fabae scopoli. J. Agric. Stud. 4(2): 107-114. 
Gould, F., G. G. Kennedy and M. T. Johnson. 1991. Effects of natural enemies on the rate of herbivore adaptation to resistant host plants. Entomol. Exp. Appl. 58(1): 1-14.

Grund, J. and L. Hirsch. 2011. The Potential of Entomopathogenic Fungal Isolates as an Environmentally Friendly Management Option against Acanthoscelides obtectus. SLU-Swedish University of Agricultural Sciences, Alnarp.

Gurulingappa, P., G. A. Sword, G. Murdoch and P. A. McGee. 2010. Colonization of crop plants by fungal entomopathogens and their effects on two insect pests when in planta. Biol. Control. 55(1): 34-41.

James, R. R., B. T. Shaffer, B. Croft and B. Lighthart. 1995. Field evaluation of Beauveria bassiana: Its persistence and effects on the pea aphid and a non-target coccinellid in alfalfa. Biocontrol Sci. Technol. 5(4): 425-438.

Knudsen, G. R., J. B. Johnson and D. J. Eschen. 1990. Alginate pellet formulation of a Beauveria bassiana (Fungi: Hyphomycetes) isolate pathogenic to cereal aphids. J. Econ. Entomol. 83(6): 2225-2228.

Korunić, Z. 2013. Diatomaceous earths: Natural insecticides. Pesticidi Fitomed. 28(2): 77-95.

Lopez, C. D. 2015. Ecological Roles of Two Entomopathogenic Endophytes: Beauveria bassiana and Purpureocillium lilacinum in Cultivated Cotton Doctoral Dissertation.

Maina, U. M., I. B. Galadima, F. M. Gambo and D. Zakaria. 2018. A review on the use of entomopathogenic fungi in the management of insect pests of field crops. J. Entomol. Zool. Stud. 6(1): 27-32.

Mascarin, G. M. and S. T. Jaronski. 2016. The production and uses of Beauveria bassiana as a microbial insecticide. World J. Microbiol. Biotechnol. 32(11): 177.

Maurer, P., Y. Couteaudier, P. A. Girard, P. D. Bridge and G. Riba. 1997. Genetic diversity of Beauveria bassiana and relatedness to host insect range. Mycol. Res. 101(2): 159-164.
McKinnon, A. C., S. Saari, M. E. Moran-Diez, N. V. Meyling, M. Raad and T. R. Glare. 2017. Beauveria bassiana as an endophyte: A critical review on associated methodology and biocontrol potential. BioControl. 62(1): 1-17.

Samish, M., H. Ginsberg and I. Glazer. 2004. Biological control of ticks. Parasitology. 129(S1): S389-S403.

Saranya, S. 2009. Biocontrol of Cowpea Aphid Aphis craccivora (Koch) using Entomopathogenic Fungi Doctoral Dissertation, Department of Agricultural Entomology, College of Horticulture, Vellanikkara.

Sayed, S. M., E. F. Ali, S. A. El-Arnaouty, S. F. Mahmoud and S. A. Amer. 2018. Isolation, identification, and molecular diversity of indigenous isolates of Beauveria bassiana from Taif region, Saudi Arabia. Egypt. J. Biol. Pest. Control. 28(1): 47.

Selvaraj, K., H. D. Kaushik and G. Rachna. 2012. Evaluation of Beauveria bassiana (Balsamo) Vuillemin against coriander aphid, Hyadaphis coriandri (Das) (Aphididae: Homoptera). J. Biol. Control. 26(1): 55-58.

Shannag, H. K. 2007. Effect of black bean aphid, Aphis fabae, on transpiration, stomatal conductance and crude protein content of faba bean. Ann. Appl. Biol. 151(2): 183-188.

Thungrabeab, M. 2007. Effect of entomopathogenic fungi, Beauveria bassiana (Balsam) and Metarhizium anisopliae (Metsch) on non target insects. Curr. Appl. Sci. Technol. 7(1): 9-11.

Vega, F. E. 2018. The use of fungal entomopathogens as endophytes in biological control: A review. Mycologia. 110(1): 4-30.

Wafaa, L. A., E. A. Abdel-Hakim and H. M. Metwally. 2017. Influence of Entomopathogenic fungus Beauveria bassiana on the mortality, reproduction and enzyme activity of the aphid adults Aphis craccivora (Koch). Middle East J. Appl. Sci. 7(3): 567-573.

Wang, Z. G. and G. R. Knudsen. 1993. Effect of Beauveria bassiana (Fungi: Hyphomycetes) on fecundity of the Russian wheat aphid (Homoptera: Aphididae). Environ. Entomol. 22(4): 874-878. 